\title{
Pirâmides alimentares: uma leitura semiótica
}

\author{
Food guide pyramids: a semiotic way of reading
}

Haydée Serrão LANZILLOTTI',

Sílvia Regina Magalhães COUTO²

Fernanda da Motta AFONSO²

\section{R E S U M O}

A semiótica é uma ciência que sistematiza e desvela o mundo dos signos, descrevendo-os e classificando-os segundo uma lógica. Existem três espécies de signos: ícones, índices e símbolos. As pirâmides alimentares são, primeiramente, ícones que podem se desenvolver até símbolos. Sob o enfoque da Nutrição, as pirâmides alimentares são consideradas ferramentas de orientação que podem transmitir conhecimentos relativos a uma alimentação considerada adequada. O objetivo deste trabalho foi avaliar o potencial comunicativo da pirâmide alimentar na perspectiva da semiótica. Neste ensaio, foram analisadas três pirâmides alimentares: United State Departament of Agriculture de 1992, de Philippi, de 1999 e de Willet e Stampfer, de 2003. O nível hierárquico em que o grupo de alimentos se encontra é o elemento informativo fundamental.

Termos de indexação: hábitos alimentares, nutrição, pirâmide alimentar.

\section{A B S T R A C T}

Semiotics is a science that systematizes and reveals the world of signs, describing and classifying them according to logic. There are three kinds of sign: icons, indexes and symbols. The food guide pyramids are, in first place, icons, which can develop into symbols. Considering the focus of Nutrition, the food guide pyramids are considered as orientation tools that can transmit knowledge related to feeding considered adequate. The objective of this paper was to show the communicative potential of the food guide pyramids from the semiotics perspective. In this trial, three food guide pyramids were analyzed. The United States Department of Agriculture, 1992, Philippi, 1999 and Willet \& Stampfer, 2003. In every food guide pyramid the hierarchic "level" in which a group of foods is found is the primordial informative element.

Indexing terms: food habits, nutrition, food guide pyramid.

\footnotetext{
1 Instituto de Nutrição, Universidade do Estado do Rio de Janeiro. Rua São Francisco Xavier, 254, 12º andar, Bloco D-12001, Maracanã, 20550-013, Rio de Janeiro, RJ, Brasil. Correspondência para/Correspondence to: H.S.LANZILLOTTI. E-mail: <haydeelan@uol.com.br>

2 Departamento de Nutrição, Universidade Gama Filho. Rio de Janeiro, RJ, Brasil.
} 


\section{N T R O D U Ç Ã O}

Os guias alimentares, ferramentas de orientação à população que visam à promoção da saúde por meio da formação de hábitos alimentares adequados, adapta conhecimentos científicos sobre recomendações nutricionais e composição de alimentos para veicular mensagens práticas que facilitem, ao maior número de pessoas, a seleção e o consumo adequados de alimentos, levando-se em consideração os fatores antropológicos, culturais, educativos, sociais e econômicos ${ }^{1}$. Um dos motivos para a sua elaboração é prevenir excessos e carências nutricionais, uma vez que a essencialidade de sua mensagem é a moderação e a proporcionalidade².

A representatividade dos guias alimentares por meio de uma expressão gráfica para os diferentes países deve ter um símbolo que melhor os represente. Deve reunir os pressupostos da nutrição adequada e eleger uma forma de comunicação capaz de causar o impacto necessário. A representação gráfica tem o propósito de ajudar o público-alvo a recordar facilmente os alimentos a incluir na dieta e suas proporções ${ }^{1}$.

As representações estão baseadas em alguns alvos ditados a partir de estudos epidemiológicos nutricionais: ingestão de uma dieta variada em alimentos, manutenção do peso ideal, redução ou aumento da massa corporal, redução dos níveis sangüíneos de gorduras saturadas e colesterol, aumento do consumo das fibras alimentares e redução da ingestão dos carboidratos simples, moderação do sódio da dieta, e consumo moderado de bebidas alcoólicas ${ }^{3}$.

Dentre os guias alimentares, destaca-se a pirâmide por sua maior divulgação. Nela os alimentos são reunidos em grupos e para estabelecer o tamanho das porções foram considerados quatro fatores: tamanho da porção típica de consumo da população, facilidade de uso, conteúdo de nutriente e tradição 4 .

Sua divulgação em grupos populacionais permite que seja reconhecida como um signo e ainda que se reflita sobre em que condições da prática dietética pode ser repensada, de modo que os conceitos de uma dieta desejável fiquem claros.

É nesse sentido que ela necessita ser entendida e utilizada como ferramenta didática na operacionalidade do processo de educação nutricional. O destinatário é a garantia da comunicação quando o desejo é democratizar o saber em alimentação e nutrição.

O nutricionista ou outro profissional de saúde familiarizado com as cognições da alimentação e nutrição sabe que uma dieta inadequada pode representar risco. A Alimentação e a Nutrição são um sistema complexo, justificando o uso de guias alimentares na tentativa de formar hábitos alimentares adequados. A comunicação dos conceitos existentes no código da alimentação e nutrição deve ser capaz de prover as condições necessárias às mudanças de comportamento no ato de comer.

O princípio semiótico de uma pirâmide alimentar é a simultaneidade entre regras nutricionais emanadas do consenso técnico-científico e respeito aos aspectos culturais do sistema de significações que representam a alimentação de uma comunidade.

Toda a análise de um objeto pode ser considerada como um problema semiótico. Assim, a análise de representações pictóricas como as pirâmides alimentares em nutrição não se furtam desse desígnio semiótico.

Neste ensaio o objetivo é evidenciar o potencial comunicativo das pirâmides alimentares.

\section{Pirâmides alimentares sob o enfoque semiótico}

A semiótica é uma ciência que sistematiza e desvela o mundo dos signos, descrevendo e classificando-os de forma lógica ${ }^{5}$. Semiótica quer dizer todas as linguagens, uma vez que o homem não vive apenas com a linguagem verbal, mas 
necessita de infinitas outras linguagens para se comunicar.

Partindo-se da definição de que a semiótica estuda todos os processos culturais que estabelecem um sistema de significações, é absolutamente necessário reconhecer que o processo de significação só existe quando existe um código. Um código é um sistema de significação que une entidades presentes e ausentes. Quando algo está presente à percepção do destinatário, sua compreensão sobre o seu significado depende de uma série de regras a que se chama código ${ }^{6}$.

Os guias alimentares e suas formas pictóricas representam um conjunto de regras (código), para alimentação adequada destinada a um determinado grupo populacional. $O$ ato de percepção do destinatário e seu comportamento interpretativo não são condições necessárias de relação de significação ${ }^{6}$, basta que o código (leis alimentares) estabeleça uma correspondência entre a quantidade de alimentos e seu correlato (pirâmide).

Um sistema de significação é um construto semiótico, ou seja, um conjunto de princípios verdadeiros ou falsos de onde se deduzem conclusões coordenadas entre si, sobre as quais se estabelece uma doutrina, opinião ou teoria ${ }^{6,7}$.

Quando um código se associa aos elementos de um sistema de cognições, cada elemento se torna a expressão do seu correspondente, que, por seu turno, se torna o conteúdo do seu par. Sempre que ocorre uma correlação entre sinal e significação reconhecida por uma sociedade e em circunstâncias previstas pelo código, existe um signo. Assim, um signo intenta representar um objeto, mesmo que pareça ser de maneira falsa, uma vez que o sistema de significações não está concebido para estabelecer uma verdade, mas aproximações da verdade ${ }^{6}$.

Segundo Pierce ${ }^{8}$ são três os signos: ícones, índices e símbolos.
- Ícones estão na primeiridade dos signos e têm a função de substituir um objeto. Um signo por primeiridade é uma imagem de seu objeto, em termos mais estritos é uma idéia, pois só pode produzi-la como interpretante, ou seja, provoca a criação de uma imagem que fica retida no cérebro. Assim, a pirâmide é um ícone.

- O índice é aquele signo que gera indicações prováveis. Está na instância da secundidade. Se um leigo está num ambulatório de nutrição e se depara com uma pirâmide alimentar, ele é capaz de perceber apenas que a imagem é algo que se refere a alimentos. O leigo não pode relacionar a pirâmide a um código alimentar, ou seja, a um conjunto de regras que determina uma dieta nutricionalmente desejável. Se um intérprete the fornece as cognições sobre esse código ele começa a possuir indicações prováveis e nesse segundo momento a pirâmide torna-se um índice. A partir daí, pode-se conjecturar sobre uma dieta adequada.

- O símbolo já exige que existam regras criadas por um intérprete, que determinará seu interpretante. Se um nutricionista ou algum profissional de saúde familiarizado com o código nutricional observa um guia alimentar, imediatamente é possível associar à imagem a idéia de uma dieta equilibrada.

Na teoria Peirceana ${ }^{(3)}$ entende-se por semiose uma ação que envolva interação entre três entes: um signo, o seu objeto e o seu interpretante ${ }^{8}$. Um signo é qualquer coisa que está para alguém no lugar de algo sob determinados aspectos ou capacidades. O signo não é o objeto. Ele apenas está no lugar do objeto . Dessa forma, as pirâmides alimentares são entes pictóricos representativos de uma alimentação equilibrada - concebida por diferentes estudiosos da nutrição -, que pretende contribuir para a melhoria da qualidade de vida de indivíduos e grupos populacionais. Assim, as pirâmides são figuras que representam padrões de uma alimentação considerada equilibrada por um grupo de especialistas, que são seus intérpretes. A

\footnotetext{
3 Teoria peirceana; relativo a Pierce; semioticista; um estudioso do conjunto de princípios, que busca explicar qualquer caso da função sígnica em termos de sistemas subjacentes correlatos de um ou mais códigos ${ }^{6}$.
} 
representação produz na mente do intérprete a combinação adequada dos alimentos relacionada aos pressupostos da Ciência da Nutrição.

Os entes signos, e entre eles a pirâmide, têm três propriedades que lhes permitem funcionar como um signo: a qualidade, a existência e seu caráter de lei. A qualidade depende da natureza do signo; a existência é a experiência concreta ou ação, e seu caráter de lei manifesta por meio de pensamentos numa série infinita de casos, que faz com que um caso singular se conforme e se amolde à sua generalidade ${ }^{10}$. Transpondo o fundamento do signo para os guias alimentares, tem-se que a qualidade é a natureza de sua representatividade gráfica: uma pirâmide para os Estados Unidos e Brasil, um prato para Inglaterra e México; um pagode para a Coréia e para a China ${ }^{2}$. A experiência é a utilização da pirâmide como um guia alimentar acessível aos leigos. Nesse sentido, se o signo é criado e não ocupa um lugar no tempo e no espaço, ele perde seu poder de funcionar como um signo. A lei, da qual a pirâmide é portadora, fará com que cada vez que uma pessoa faça sua dieta habitual seja entendida por ela a necessidade de escolher os alimentos de forma a obedecer princípios de quantidade, qualidade, harmonia e adequação.

Ainda sob o prisma da semiótica, é necessário entender o conceito de interpretante. O interpretante não é o intérprete; pois é algo que assegura a validade do signo, mesmo na ausência do intérprete, ou seja, consiste naquilo que o signo está apto a produzir numa mente interpretadora, sem interlocutores. Por outro lado, o especialista tem a pirâmide como uma ferramenta comunicativa de tradução pictórica de uma alimentação desejável, uma vez que possui cognições em Comunicação e Nutrição que ainda não foram democratizadas ao leigo. Então, o intuito do uso de um ícone no processo de comunicação em nutrição é aproximar as percepções dos intérpretes (leigo e especialista) na construção do interpretante. Mas se a pirâmide for adotada como uma forma de intervenção educativa para democratizar o saber em Nutrição, a fim de que todas as pessoas sejam capazes de compor sua dieta de forma equilibrada, a pirâmide vai se tornando um interpretante na medida de seu uso como forma de comunicação. A partir desse momento ela se torna um signo de uma semiose ilimitada.

\section{A semiose ilimitada da pirâmide alimentar}

O intuito da criação de guias alimentares, traduzidos em pirâmides à semelhança dos ícones adotados nos Estados Unidos, vai além da formação de uma opinião, uma vez que se espera que a cognição abra passagem para um comportamento desejável.

Procura-se, durante décadas, buscar formas pictóricas que representem a distribuição adequada dos alimentos nas refeições e ainda que possibilite a compreensão da população sobre o arranjo harmonioso dos alimentos.

O desafio é encontrar a melhor forma comunicativa de realizar tal intento.

O Departamento de Agricultura dos Estados Unidos (USDA) apresentou oficialmente o Guia da Pirâmide Alimentar em $1992^{11}$, sendo propostos quatro níveis. O primeiro nível compreende o grupo dos pães, cereais, arroz e massas, com seis a onze porções; o segundo, o grupo das verduras e legumes, com três a cinco porções e o grupo das frutas, com duas a quatro porções; o terceiro nível, grupo do leite, iogurte, queijos, com duas a três porções e grupo das carnes, aves, peixes, leguminosas, ovos e nozes, com duas a três porções; e o quarto nível, grupo das gorduras, óleos e açúcares com a recomendação de uso moderado.

A mensagem principal propõe a diminuição do consumo de gorduras e óleos, e o consumo aumentado de carboidratos complexos, como pães, cereais e massas. A pirâmide também recomenda quantidades generosas de verduras e legumes, incluindo a batata com aproximadamente $20 \%$ de carboidrato complexo.

A introdução da pirâmide com as porções de alimentos de cada grupo alimentar como um 
signo da alimentação considerada correta e sua favorável repercussão na população americana do Norte foi um dos fatores que incentivaram a criação de uma outra pirâmide que traduzisse o consumo e o modo de preparo dos alimentos brasileiros. Assim, Philippi ${ }^{12}$ propôs uma pirâmide que leva em consideração os hábitos alimentares da população brasileira. A segurança alimentar leva em conta, entre suas premissas, que se considere a dimensão do patrimônio cultural intrínseco nas preferências alimentares das comunidades locais e nas suas práticas de preparo e consumo ${ }^{13}$.

A pirâmide brasileira também foi construída em quatro níveis. O primeiro nível compreende o grupo dos cereais, pães, tubérculos, raízes (farinhas, massas, bolos, biscoitos, cereais matinais, arroz) com cinco a nove porções; o segundo nível, o grupo das hortaliças, com quatro a cinco porções e grupo das frutas com três a cinco porções; o terceiro nível, o grupo do leite e produtos lácteos, com três porções e grupo das carnes e ovos com uma a duas porções e o grupo das leguminosas com uma porção; o quarto nível, o grupo dos óleos e gorduras, com uma a duas porções e o grupo dos açúcares e doces com uma a duas porções. Estabeleceu as porções de alimentos com base em três dietas com valores de energia de 1600, 2200 e $2800 \mathrm{kcal}$, segundo o que recomenda o Continuing Survey of Food Intake ${ }^{14}$. Os alimentos foram distribuídos em seis refeições com o peso em gramas e medidas caseiras correspondendo às respectivas porções. Os alimentos foram reunidos em seis grupos e alocados nos quatro níveis citados anteriormente.

Willet \& Stampfer ${ }^{15}$ apresentaram um outro Guia da Pirâmide Alimentar, no qual os grupos de alimentos se apresentam em seis níveis, considerando-se o desgaste energético advindo da atividade física, que está representada na base de sustentação da pirâmide, o que a diferencia das anteriormente citadas. Os autores dividiram sua pirâmide nos seguintes níveis: o primeiro, compreendendo o grupo dos cereais integrais e dos óleos vegetais; o segundo, o grupo das verduras e legumes e o grupo das frutas com duas a três porções; o terceiro nível, o grupo das nozes, castanhas e leguminosas com uma a três porções; o quarto, o grupo dos pescados, aves e ovos com zero a duas porções; o quinto nível, o grupo dos laticínios ou suplemento de cálcio com uma a duas porções; e finalmente o sexto nível, grupo das carnes vermelhas e manteiga e grupo do arroz branco, pão branco, batata e massas.

Enquanto na pirâmide do USDA as carnes, ovos e leguminosas encontram-se dentro de um mesmo grupo, na de Willet \& Stampfer ${ }^{15}$ as leguminosas alocam-se em um único grupo juntamente com nozes e castanhas. Em Philippi, as leguminosas foram agrupadas isoladamente por serem comuns na alimentação básica do brasileiro, principalmente o feijão.

Note-se que nesse lexema não está explicitado para os grupos do primeiro nível e para o grupo das verduras no segundo nível o número de porções de consumo desejável. No segundo caso, sugere-se uso abundante. Nessa pirâmide, as nozes saem do grupo de alimentos eminentemente protéicos (creditado na pirâmide do USDA) e passam a figurar nos energéticos. Importante notar a inversão das posições que assumem o óleo vegetal, que sai do quarto nível na pirâmide do USDA ${ }^{11}$ para o primeiro nível na de Willet \& Stampfer ${ }^{15}$; provavelmente foi resultado da incorporação de novas informações nutricionais nos liames dos padrões de alimentação.

A carne vermelha com a recomendação de duas a três porções junta-se à manteiga e assume o topo da pirâmide ${ }^{15}$, agora como vilões de uma alimentação considerada adequada. Nessa nova pirâmide, se propõe o uso de suplemento de cálcio e vitaminas múltiplas e ainda o uso de álcool com moderação, além dos alimentos preconizados nas outras pirâmides em apreço. Se o desejo é democratizar o saber em Nutrição, faz-se necessário também indicar as doses de bebidas alcoólicas consideradas 
desejáveis, uma vez que moderação pode ser interpretada de diferentes formas por abstêmios e alcoólatras.

Willet \& Stampfer ${ }^{15}$ alertam que um número crescente de pesquisas indica que a pirâmide proposta pelo USDA ${ }^{11}$ estava adaptada ao paradigma nutricional e dietético da época.

No que tange às gorduras, as pirâmides do USDA ${ }^{11}$ e de Philippi ${ }^{12}$ concentram as gorduras saturadas e insaturadas no mesmo grupo e sugerem sua restrição, já que estão alocadas no topo da pirâmide. Willet \& Stampfer ${ }^{15}$ separam as gorduras em dois grupos, alocando-as radicalmente contra a sugestão do USDA. Óleos vegetais estão na base da pirâmide, significando que devem ser consumidos abundantemente enquanto gorduras saturadas estão alocadas no topo.

Entretanto, os intérpretes das pirâmides USDA $^{11}$, Philippi ${ }^{12}$ e Willet \& Stampfer ${ }^{15}$ não levaram em consideração o grau de insaturação da molécula de ácido graxo quando criaram os grupos de alimentos em suas pirâmides.

Tanto o USDA ${ }^{11}$ quanto Philippi ${ }^{12}$ não fazem distinção entre os cereais refinados $\mathrm{e}$ integrais, alocando-os no mesmo grupo na base da pirâmide. Willet \& Stampfer ${ }^{15}$ contribuíram significativamente para a informação do interpretante quando separam os cereais em dois grupos, alocando os integrais na base (consumo liberado) e os refinados no topo (consumo moderado). Essa dicotomia é relevante uma vez que consumir carboidratos refinados mesmo que moderadamente como indicado pelo USDA ${ }^{11} \mathrm{e}$ Philippi ${ }^{12}$ pode elevar os níveis de glicose no sangue, que também estão associados a alto risco de doenças cardiovasculares. Nessa discussão não é suficiente no paradigma dietético indicar somente a quantidade e a classificação dos carboidratos que devem ser ingeridos, mas separá-los como proposto por Willet \& Stampfer ${ }^{15}$.

O índice glicêmico é a ordenação de alimentos baseada na resposta de glicose sangüínea pós-prandial comparada com um alimento referência ${ }^{16}$. Ele funciona como um parâmetro complementar da composição dos alimentos. Lang ${ }^{17}$ mostrou não existir relação entre o índice glicêmico e a classificação dos carboidratos, isto é, não importa o fato de eles serem simples ou complexos e nem a relação entre açúcares e amidos, confirmando que a distinção não reflete seu efeito fisiológico. A questão relevante na informação veiculada na pirâmide seria destacar o consumo de fibra solúvel que tem a capacidade de diminuir o índice glicêmico do alimento, já que ela aumenta a viscosidade no lúmen, diminuindo a velocidade de absorção da glicose. Essa é a razão para Willet \& Stampfer ${ }^{15}$ privilegiarem alimentos ricos em fibras em sua pirâmide, como os cereais integrais, frutas e hortaliças.

Nenhum dos intérpretes dos ícones estudados subdividem o grupo dos cereais, tubérculos e raízes, o que leva a crer sobre a desatenção dispensada às gorduras hidrogenadas presentes em bolos, biscoitos e outros produtos de panificação. O processo de hidrogenação, segundo Moretto ${ }^{18}$, gera os ácidos graxos trans que estão sendo associados ao alto risco de doenças cardiovasculares por contribuírem com a formação de placas de ateroma no lúmen das artérias.

Willet \& Stampfer ${ }^{15}$ sugerem o uso de suplemento vitamínico e atividade física. Deveria ser indicado que o somatório dos valores nutricionais da dieta mais o suplemento não podem ultrapassar os valores de referência Reference Dietary Intake (RDIs) ${ }^{19}$. Ao se ultrapassarem os valores de referência há mudança de paradigma, ou seja, do nutricional para o medicamentoso.

Em todas as pirâmides estudadas a indicação de consumo é a resultante da interação entre verticalidade (nível) e horizontalidade (grupos). O nível é o elemento informativo fundamental, uma vez que determina a liberação ou restrição dos grupos alimentares.

Considerando esses aspectos na análise semiótica dos guias alimentares, acredita-se que a maior dificuldade é encontrar um ícone que seja do domínio público, o qual tenha potencialmente 
o poder comunicativo daquilo que se queira transmitir.

O processo semiótico tem possibilidades ilimitadas na construção do interpretante. É um devir, isto é, um "vir a ser" com sucessivas mudanças que se criam e se recriam. Ao olhar uma pirâmide pode-se imaginar outra capaz de incorporar outros elementos da contemporaneidade do código nutricional e alimentar. Aquele que percebe o "vir a ser" dos guias alimentares assume necessariamente a posição de um intérprete dinâmico daquela semiose específica, porque a semiose começa na criação de um ícone até atingir o status de símbolo, possibilitado por uma lógica que obriga ao intérprete ultrapassar a subjetividade da imagem de uma pirâmide com alimentos superpostos para uma lógica que sustente os conceitos de uma dieta equilibrada em substâncias alimentares (nutrientes e não nutrientes).

\section{COMENTÁRIOS FINAIS}

O nível em que os alimentos foram hierarquizados é o elemento informativo fundamental, uma vez que determina suas proporções. Das três pirâmides analisadas, a pirâmide proposta por Willet \& Stampfer ${ }^{15}$ é a que mais se aproxima do código nutricional. A proposta por Philippi ${ }^{12}$ tem o mérito de ter articulado recomendações dietéticas e aspectos culturais da alimentação brasileira.

A pirâmide alimentar ou qualquer outro signo é capaz de explicar, em seus próprios termos, a sucessão de informações sobre uma alimentação adequada num contínuo. As várias pirâmides criadas tornam-se um sistema auto-explicativo que denota a evolução do saber em Nutrição na intenção de transmitir à população as informações da maneira adequada de escolher os alimentos para compor sua refeição.

O interpretante de uma pirâmide alimentar deve ser algo mais do que uma distribuição de alimentos hierarquizada; ele deve inferir o desenvolvimento de todas as possibilidades implícitas no signo.

O escopo deste ensaio foi revelar o potencial comunicativo das pirâmides alimentares e mostrar que os guias alimentares, entre eles as pirâmides, são sistemas de significações que abrigam um conjunto de princípios, dos quais se deduzem conclusões coordenadas entre si, sobre as quais se estabelecem modos de se alimentar. Não importa se os grupos alimentares são organizados e reorganizados à luz de novos conhecimentos, ou se a representação gráfica é uma pirâmide ou qualquer outro signo, o que importa é ampliar as redes de comunicação que facilitem o intercâmbio da experiência e de novas cognições. Nesse sentido, o código pode ser nutrido de novas informações por meio de uma cooperação técnico-científica.

O relevante nos guias alimentares não é seu contorno, mas sobretudo as possibilidades teóricas e as funções de comunicação da semiose atribuídas às pirâmides alimentares em termos de sistemas subjacentes correspondentes a um código nutricional que expressa as cognições do sistema complexo nutrição-saúde.

Uma das críticas possíveis de serem levantadas à proposta de Philippi ${ }^{12}$ na escolha da representação do guia alimentar por uma pirâmide para representar a alimentação equilibrada no Brasil é a transferência de um signo que parece ter dado certo nos Estados Unidos. Será que o povo brasileiro adotou integralmente a expressão de uma alimentação correta sob a forma da pirâmide? Ou a pirâmide pode ter outra conotação para o destinatário?

\section{REFERÊ NCIAS}

1. Pena M, Palma, VM. Guias de alimentación en America Latina. I Workshop Instituto Danone: Alimentação equilibrada para a população brasileira; 1998; Florianópolis, Brasil. Florianópolis: Instituto Danone, Sociedade Brasileira de Alimentação e Nutrição; 1998. 
2. Painter J, Rah JH, Lee YK. Comparison of international food guide pictorial representations. J Am Diet Assoc. 2002; 102(4):483-9.

3. Welsh S, Davis C, Shaw A. Development of the food guide pyramid. Nutr Tod. 1992; 27(6): $12-23$.

4. United States Departament of Agriculture. Serving sizes in the food guide pyramid and on the nutrition facts label: What's different and why? Washington (DC): Center of Nutrition Policy and Promotion; 2000. Insight 22.

5. Puppi Al. Semiótica e desenho industrial. In: Semana de Semiótica 1. Curitiba: SECE/Biblioteca Pública do Paraná; 1985. p.59-76.

6. Eco U. Tratado geral de semiótica. São Paulo: Perspectiva; 1991.

7. Ferreira $A B H$. Dicionário Aurélio escolar da língua portuguesa. Rio de Janeiro: Nova Fronteira; 1988.

8. Pierce CS. Semiótica. São Paulo: Perspectiva; 1995.

9. Santaella L. O que é semiótica. 4.ed. São Paulo: Brasiliense; 1986.

10. Santaella L. Semiótica aplicada. São Paulo: Pioneira Thomson Learning; 2002.

11. Food guide piramyd. A guide to daily food choices. Washington (DC): US Department of Agriculture, Human Nutrition Information Service. 1992. Home and Garden Bulletin n.232.

12. Philippi ST, Latterza AR, Cruz, ATR, Ribeiro LC. Pirâmide alimentar adaptada: guia para a escolha dos alimentos. Rev Nutr. 1999; 12(3):65-80.
13. Kennedy ET, Ohls J, Carlson S, Fleming K. The healthy Eating Index: design and applications. J Am Diet Assoc. 1995; 95(10):1103-8.

14. Maluf RS, Menezes F. Segurança alimentar [homepage on the Internet]. [Acessado 2003 jan 25]. Disponível em: http://www.dhnet.org.br/ direitos/sos/alimentação/tconferências.html,2002

15. Willet WC, Stampfer MJ,. As novas bases da pirâmide alimentar [homepage on the Internet]. 2003. [Acessado 2003 out 6]. Disponível em: URL:http://www.2.uol.com.br/sciam/ materia_capa_14.html

16. Foster-Powel K, Holt SH, Brand-Miller JC. International tables of glycemic index and glycemic load values. Am J Clin Nutr. 2002; 76(1):5-56.

17. Lang $V$. Alimentos à base de cereais no café da manhã: a importância do índice glicêmico. Simpósio Novas Tendências sobre a Importância dos Carboidratos na Nutrição; 1999 dez; São Paulo, Brasil. São Paulo: Danone; 1999.

18. Moretto E, Fett R. Tecnologia de óleos e gorduras vegetais na indústria de alimentos. São Paulo: Varela; 1998.

19. Trumbo P, Schlicker S, Yates AA, Poos M. Food and Nutrition Board of the Institute of medicine, the National Academics. Dietary reference intakes for energy, carbohydrate, fiber, fat, fatty acids, cholesterol, protein and amino acids. J Am Diet Assoc. 2002; 102(11):1621-30.

Recebido para publicação em 10 de maio de 2004 e aceito em 12 de abril de 2005. 